\title{
Effects of Methylmercuric Chloride and Bis (Methylmercuric) Selenide on Responses of Isolated Intestinal Smooth Muscle of the Guinea-Pig
}

\author{
Yasue Fukushi and Reiko Yamamoto* \\ Department of Applied Physiology, Tohoku University \\ School of Medicine, Sendai 980, *Department of Public \\ Health, Tohoku University of School of Medicine, Sendai \\ 980
}

\begin{abstract}
Fukushi, Y. and Yамамото, R. Effects of Methylmercuric Chloride and Bis (Methylmercuric) Selenide on Responses of Isolated Intestinal Smooth Muscle of the Guinea-Pig. Tohoku J. exp. Med., 1985, 145(3), 243-249— The neurologically toxic substance, methylmercury, is detoxicated by simultaneous application of selenite. In vivo formation of bis (methylmercuric) selenide has been suggested as the mechanism of detoxication by selenite. By using isolated guinea-pig taenia coli preparations, the effects of methylmercuric chloride and bis (methylmercuric) selenide on contractile responses to nerve and direct stimulation were investigated. Application of either drugs scarcely affected contractile responses to direct stimulation. However, contractile responses to nerve stimulation were severely reduced by methylmercuric chloride. The effect of bis (methylmercuric) selenide was considerably weaker than methylmercuric chloride. The site blocked by methylmercuric chloride and bis (methylmercuric) selenide in the taenia preparation was discussed methylmercuric chloride (MMC); bis (methylmercuric) selenide (BMS); guinea-pig taenia coli
\end{abstract}

Conspicuous manifestations of methylmercury poisoning are mainly neurological disorders (Takeuchi et al. 1962 ; Bakir et al. 1973). Selenium compounds, when administered to animals, exert a protective effect against the neurotoxicity of methylmercury (Ganther et al. 1972 ; Iwata et al. 1973 ; Ohi et al. 1976). Sumino et al. $(1977,1979)$ reported that methylmercury bound to proteins can be released by adding selenite under physiological conditions in vitro in the form of free methylmercury, which was later identified as not a free methylmercury but a complex consisting of methylmercury and selenium, formulated as bis (methylmercuric) selenide ( $\mathrm{BMS} ;\left(\mathrm{CH}_{3} \mathrm{Hg}\right)_{2} \mathrm{Se}$ ) (Naganuma and Imura 1980). Recently, BMS was actually demonstrated in tissues of the animal administered methylmercury with selenite (Iwata et al. 1981 ; Masukawa et al. 1982). 
If the formation of BMS is involved in the detoxication mechanism of methylmercury in vivo, the toxic action of BMS should be expected to be lesser than methylmercury. In fact, potencies of BMS to inhibit the enzymatic activities of glucose 6-phosphate dehydrogenase, catalase and trypsin are markedly weaker than methylmercuric chloride (MMC) (Mochizuki et al. 1982).

However, as the toxic actions of methylmercury are neurological, to know toxication and detoxication mechanism of methylmercury it needs to accumulate data on inhibitory effects of MMC and its derivatives by using living nerve-muscle preparations.

In the present experiments, we studied the inhibitory effects of MMC and BMS on the contractile responses of the isolated intestinal smooth muscle, taenia coli, of the guinea-pig to direct and nerve stimulation. The preliminary study has been reported (Fukushi et al. 1983).

\section{Materials and Methods}

\section{Preparation of material}

Male guinea-pigs were killed by a blow on the head and strips of taenia coli were dissected from the caecum. The strip trimmed approximately $1 \mathrm{~cm}$ in length was suspended in a small organ bath and perfused with the modified Krebs solution (Fukushi and Suzuki 1983). The bath was gassed with $95 \% \mathrm{O}_{2}$ and $5 \% \mathrm{CO}_{2}$ and its temperature was kept at $34^{\circ}$ C. The resting tension of each strip was adjusted at $200 \mathrm{mg}$ and the changes in tension induced were recorded isometrically with a force transducer (Grass, FT-10). Before the start of experiments, all preparations were allowed to equilibrate for $45 \mathrm{~min}$ in the modified Krebs solution containing ethanol at the same concentration as the test solution. To test the effect of drug, the solution already present was quickly siphoned off from the organ bath and replaced by the drug solution; this procedure took only several seconds. However, sudden changes in the level of the solution in the organ bath caused large artifacts, so that recovery of the position of the recording pen to the original level was checked and the recording system was adjusted. For selective stimulation of the intramural nerves, square wave pulses of $0.3 \mathrm{msec}$ duration at a frequency of $5 \mathrm{~Hz}$ were delivered for 5 sec transmurally to the taenia strip through bipolar stimulating electrodes made of $\mathrm{Ag}-\mathrm{AgCl}$ rings. For direct stimulation of muscles, the strip was passed through field stimulation of $\mathrm{AC}(2 \mathrm{~V} / \mathrm{cm}$, $50 \mathrm{~Hz}$ ). The strength of stimulus was sufficient to produce the maximal responses.

\section{Drugs}

BMS was donated by Prof. N. Imura and Dr. A. Naganuma, School of Pharmaceutical Sciences, Kitasato University. MMC was purchased from Wako Pure Chemical Ind. One-hundredth mmoles of each drug were dissolved in $1 \mathrm{ml}$ of absolute ethanol as stock solutions. Aliquots from the stock solution were diluted by the modified Krebs solution to give desired concentrations. Final concentration of ethanol in the drug solution for test was always kept below $1 \%$ to avoid harmful effects on responsiveness of the material.

\section{Statistical analysis}

Values are expressed in terms of means \pm S.E. Differences between mean values were analysed with Student $t$-test, and were judged to be significant when $p$ values were less than 0.05 . 


\section{RESULTS}

\section{Effects of $M M C$ and $B M S$ on contractile responses of taeniae coli}

Fig. 1 shows examples of contractile responses of 2 taenia preparations to transmural stimulation of enteric nerves before and during application of MMC and BMS of which concentrations were $25 \mu \mathrm{M}$ equivalent to methylmercuric moiety, respectively.

MMC markedly reduced the responses immediately after its application and only tiny responses were observed several minutes later (Fig. 1A). With the application of BMS the inhibitory effect was small at first and gradually increased with time (Fig. 1B). Transient contractions found immediately after addition of both drugs (arrows in Fig. 1A and 1B) may have been artifacts due to replacement of the solution in the organ bath. All contractile responses to transmural stimulation of nerves observed in the present study, were completely blocked by atropine (data not shown).

Effects of MMC and BMS on the contractile responses to nerve stimulation and direct stimulation of muscles at various exposure times were quantatively studied. The effect of a drug was expressed by the height of the contractile response during exposure to the drug in percentages of that before its application. The concentrations of MMC and BMS used were $50 \mu \mathrm{M}$ equivalent to methylmercuric moiety, respectively. The results are shown in Fig. 2.

MMC markedly inhibited the contractile responses to transmural stimulation (Fig. $2 \mathrm{~A}$ ). The response was $27 \pm 11 \%$ at $5 \mathrm{~min}$ and waned completely at $15 \mathrm{~min}$. The inhibitory effect of MMC could not be recovered by washing and increased further with time. In contrast MMC inhibited only slightly the response to direct stimulation of muscles. At $5 \mathrm{~min}$ the response was $84 \pm 17 \%$ but no statistical significance was found $(n=5)$. Small decrease of the response was observed with time, the response being $80 \pm 6 \%(\mathrm{n}=5 ; p<0.01)$ at $15 \mathrm{~min}$.

The inhibitory effect of BMS on the contractile responses to transmural stimulation was pronouncedly smaller than that of MMC (Fig. 2B). The response was $86 \pm 4 \%$ and $43 \pm 8 \%$ at 5 and $15 \mathrm{~min}$, respectively. The response to direct

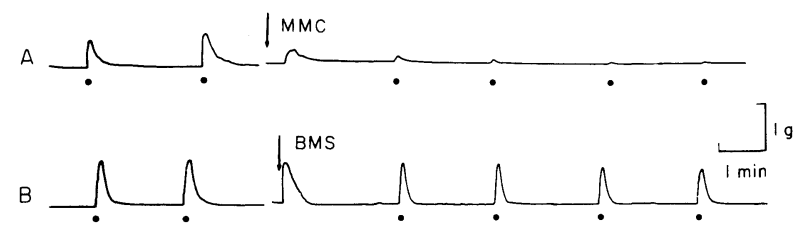

Fig. 1. Centractions of isolated taenia preparations to transmural stimulation of enteric nerves and the effects of MMC and BMS on the contractile responses. Both drugs were used at a concentration of $25 \mu \mathrm{M}$ equivalent to methylmercuric moiety. MMC and BMS were tested in different preparations. Stimuli, square wave pulses $0.3 \mathrm{msec}$ duration at $5 \mathrm{~Hz}$, was applied for 5 sec at times indicated by dots. 

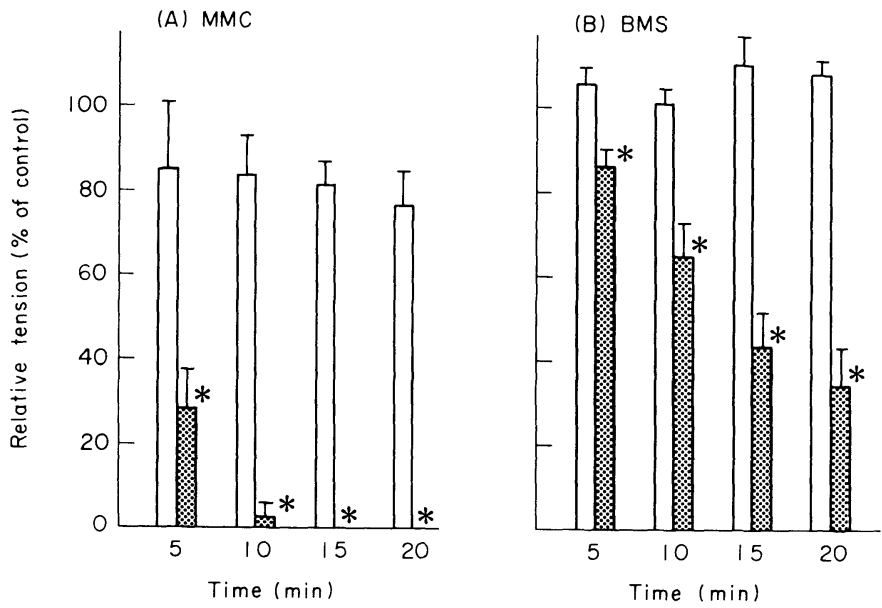

Fig. 2. Decrease in the contractile response of isolated taenia preparations to nerve stimulation and direct stimulation of the muscle with exposure time to MMC and BMS. Both drugs were used at a concentration of $50 \mu \mathrm{M}$ equivalent to methylmercuric moiety. Open column, direct stimulation; dotted column, nerve stimulation. The response was measured by the height of peak of each contraction curve. The effect of drugs was expressed by percentage of the response taking that before drug application as $100 \%$. Asteriks indicate significant difference from the control experiment $(p<0.05)$. Each value represents the mean of 5 to 7 experiments and vertical bars indicate s.E.

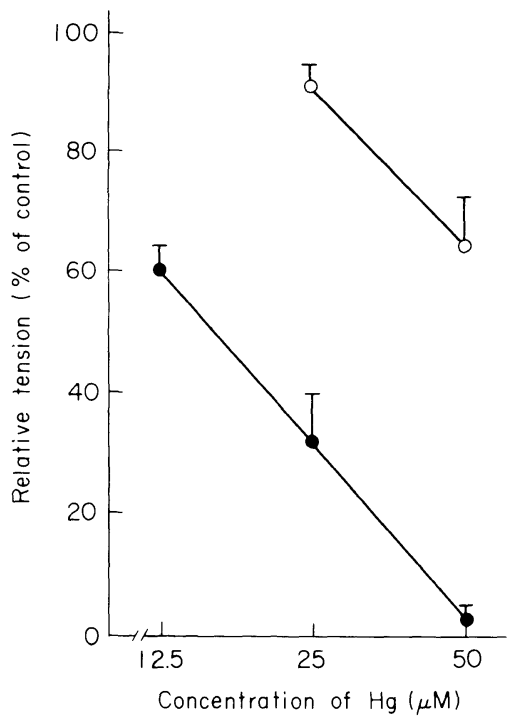

Fig. 3. Relations between concentrations of MMC and contractile responses of isolated taenia preparation to transmural stimulation. Exposure time to drugs was 10 min. Each value represents the mean of 5 to 7 experiments and vertical bars indicate S.E. 
stimulation of muscles was not affected at all by application of BMS at any exposure time. Even at the exposure time for $40 \mathrm{~min}, 91 \pm 6 \%$ response was observed $(n=4 ; p>0.05)$. The inhibitory effect could be recovered by washing the preparation exposed within $20 \mathrm{~min}$.

\section{Concentration-response curves for $M M C$ and $B M S$}

The contractile responses to transmural stimulation were measured for the preparations exposed to various concentrations of each drug for $10 \mathrm{~min}$ and the concentration-response curves were made (Fig. 3). The exposure time for $10 \mathrm{~min}$ was adopted to maximize the inhibitory effect on responses and minimize the direct effect of drugs on muscles as shown in Fig. 2A. The concentration-response curve for BMS was located on the right of that for MMC, the slopes of both curves being similar.

\section{Discussion}

There are many investigations showing that toxicity of methylmercury is attributed to damages of neural functions (Review : Chang 1977). In the sciatic nerve-sartorius muscle preparation of the frog, MMC blocks effectively muscle twitches evoked by indirect stimulation (Juang 1976a) without changing the resting membrane potential or membrane resistance (Juang 1976b). In the squid axon, MMC inhibits action potentials without changing the resting membrane potential or membrane resistance, the inhibition of the sodium activation mechanism being responsible (Schrivastav et al. 1976). Furthermore, in the sympathetic ganglion of the rat, MMC seems to inhibit the release of acetylcholine from presynaptic nerve terminals (Alkadhi and Taha 1982). The activity of choline acetyltransferase in the brain of rat is also inhibited by MMC $(10 \mathrm{mg} / \mathrm{kg} /$ day, for 3-15 days) (Omata et al. 1982).

On the inhibitory mechanism of contractile responses to nerve stimulation by methylmercury in the nerve-muscle preparation, we consider the following five possibilities; (1) blockage of conduction mechanism of the nerve, (2) inhibition of synthetic enzymes of transmitters, (3) suppression of release of transmitters, (4) depression of postsynaptic membrane excitability and (5) damage of contractile machinery of muscles.

Our results obtained in the present experiments clearly showed that the contractile machinery of the MMC-treated preparation of taenia was nearly intact. From the literatures mentioned above the possibility of depression of the postsynaptic membrane excitability may be ruled out. The inhibition of synthetic enzymes of transmitters must take much time for the effect to be realized. Eventually, the conduction mechanism and releasing mechanism of transmitters remain as the candidate for target of MMC. At present, we have no knowledge enough to choose either possibility or both.

The general feature of actions of BMS on the taenia preparation resembles 
that of MMC ; both drugs have no marked effect on the contractile machinery of the muscles during the application times and hence are supposed to affect the nerves and/or the receptors of muscle membrane, although the latter possibility is rather small as discussed above. However, they differ in the strength of toxicity ; BMS needs concentration of approximately 5 times than MMC to cause the same extent of inhibition (Fig. 3).

In summerizing, the results obtained in this study suggest the scheme that MMC incorporated in animal tissues to block the functions of the nerve and/or the receptors of muscle membrane and is detoxicated by forming a complex with selenite, which displays a remakably weakened toxicity.

\section{Acknowledgments}

We thank Prof. N. Imura and Dr. A. Naganuma, School of Pharmaceutical Sciences, Kitasato University, for their gift of BMS. We are also grateful to emerites Prof. T. Suzuki for his valuable advice for this study and Mr. Y. Nakajima for his help in making photographs.

\section{References}

1) Alkadhi, K.A. \& Taha, M.N. (1982) Antagonism by calcium of the inhibitory effect of methylmercury on symphathetic ganglia. Arch. Toxicol., 51, 285-294.

2) Bakir, F., Domaluji, S.F., Amin-Zaki, L., Murtadha, M., Khalidi, A., Al-Rawi, N.Y., Tikriti, S., Dhahir, H.I., Clrkson, J., Smith, J.C. \& Doherty, R.A. (1973) Methylmercury poisoning in Iraq. Science, 181, 230-241.

3) Chang, L.W. (1977) Neurotoxic effects of mercury-A review. Environ. Research, 14, 329-373.

4) Fukushi, Y. \& Suzuki, T.S. (1983) Effects of homopantothenic acid on intestinal smooth muscles. Tohoku J. exp. Med., 140, 45-51.

5) Fukushi, Y., Yamamoto, R., Naganuma, A. \& Imura, N. (1983) Effects of methylmercuric chloride, selenide and bis (methylmercuric) selenide on the enteric nerves and smooth muscles of guinea-pig intestine. Jap. J. Smooth Muscle Res., 19, 348-351. (Japanese)

6) Ganther, H.E., Gondie, C., Sunde, M.L., Kopecky, M.J., Wanger, P.A., Oh, S.H. \& Hoestra, W.G. (1972) Selenium: Relation to decreased toxicity of methylmercury added to diets containing tuna. Science, 175, 1122-1124.

7) Iwata, H., Okamoto, H. \& Ohsawa, Y. (1973) Effect of selenium of methylmercury poisoning. Res. Commun. Chem. pathol. pharmacol., 5, 673-680.

8) Iwata, H., Masukawa, T., Kito, H. \& Hayashi, M. (1981) Involvement of tissue sulfhydryls in the formation of a complex of methylmercury with selenium. Biochem. Pharmacol., 30, 3159-3163.

9) Juang, M.S. (1976a) Depression of frog muscle contraction by methylmercuric chloride and mercuric chloride. Toxicol. appl. Pharmacol., 35, 183-185.

10) Juang, M.S. (1976b) An electrophysiological study of methylmercuric chloride on the sciatic nerve-sartorius muscle preparation of the frog. Toxicol. appl. Pharmacol., 37, $339-348$.

11) Masukawa, T., Kito, H., Hayashi, M. \& Iwata, H. (1982) Formation and possible role of bis (methylmercuric) selenide in rats treated with methylmercury and selenite. Biochem. Pharmacol., 31, 75-78.

12) Mochizuki, Y., Kobayashi, T. \& Doi, R. (1982) In vitro effects of mercury-selenium compounds on enzymes. Toxicol. Lett., 14, 201-206. 
13) Naganuma, A. \& Imura, N. (1980) Bis (methylmercuric) selenide as a reaction product from methylmercury and selenite in rabbit blood. Res. Commun. Pathol. Pharmacol., 27, 163-173.

14) Ohi, G., Nishigaki, S., Seki, H., Tamura, Y., Maki, T., Konno, H., Ochiai, S., Yamada, H., Shimamura, Y., Mizoguchi, I. \& Yague, H. (1976) Efficacy of selenium in tuna and selenite in modifying methylmercury intoxication. Environ. Res., 12, 49-58.

15) Omata, S., Hirakawa, E., Daimon, Y., Uchiyama, M., Nakashita, H., Horigome, T. \& Sugano, H. (1982) Methylmercury-induced changes in the activities of neurotransmitter enzymes in nervous tissues of the rat. Arch. Toxicol., 51, 285-294.

16) Sumino, K., Yamamoto, R. \& Kitamura, S. (1977) A role of selenium against methylmercury toxicity. Nature, 268, 73-74.

17) Sumino, K., Yamamoto, R. \& Kitamura, S. (1979) Mechanism of methylmercury release from bound type in bloodstream or tissues. Biochem. Biophys. Res. Commun., 86, 735-741.

18) Schrivastav, B.B., Brodwick, M.S. \& Narahashi, T. (1976) Methylmercury : Effects on electrical properties of squid axon membranes. Life Sci., 18, 1077-1082.

19) Takeuchi, T., Morikawa, N., Matsumoto, H. \& Shiraishi, Y. (1962) A pathological study of Minamata disease in Japan. Acta neuropathol., 2, 40-57. 